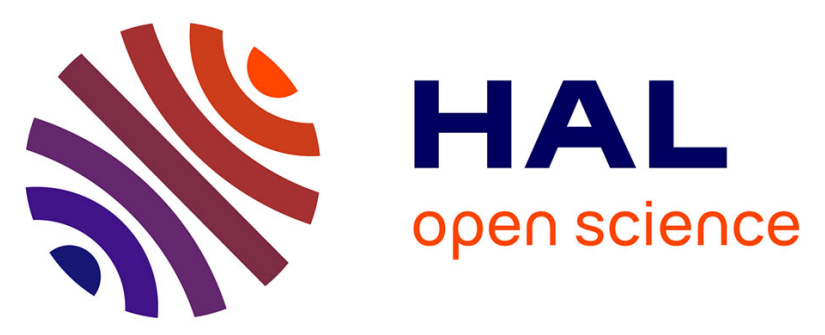

\title{
Disentangling the influence of local and landscape factors on alpha and beta diversities: opposite response of plants and ground-dwelling arthropods in wet meadows
}

Denis Lafage, Sébastien Maugenest, Jan-Bernard Bouzillé, Julien Pétillon

\section{- To cite this version:}

Denis Lafage, Sébastien Maugenest, Jan-Bernard Bouzillé, Julien Pétillon. Disentangling the influence of local and landscape factors on alpha and beta diversities: opposite response of plants and ground-dwelling arthropods in wet meadows. Ecological Research, 2015, 30 (6), pp.1025-1035. 10.1007/s11284-015-1304-0 . hal-01205359

HAL Id: hal-01205359

https://hal-univ-rennes1.archives-ouvertes.fr/hal-01205359

Submitted on 7 Jan 2016

HAL is a multi-disciplinary open access archive for the deposit and dissemination of scientific research documents, whether they are published or not. The documents may come from teaching and research institutions in France or abroad, or from public or private research centers.
L'archive ouverte pluridisciplinaire HAL, est destinée au dépôt et à la diffusion de documents scientifiques de niveau recherche, publiés ou non, émanant des établissements d'enseignement et de recherche français ou étrangers, des laboratoires publics ou privés. 
Disentangling the influence of local and landscape factors on alpha and beta diversities: opposite response of plants and ground-dwelling arthropods in wet meadows

Denis Lafage ${ }^{\mathrm{a}, \mathrm{b}, *}$, Sébastien Maugenest ${ }^{\mathrm{b}}$, Jan-Bernard Bouzilléd ${ }^{\mathrm{d}}, \&$ Julien Pétillon ${ }^{\mathrm{a}}$

a Université de Rennes 1, EA 7316, 263 Avenue du Général Leclerc, CS 74205, 35042 Rennes Cedex, France

${ }^{\text {b} U n i v e r s i t e ́ ~ d ' A n g e r s, ~ L U N A M, ~ G E C C O, ~} 2$ Boulevard Lavoisier, 49045 Angers, France.

c Université de Rennes 1, UMR CNRS 6553 Ecobio, Campus Beaulieu, 263 Avenue du Général Leclerc, 35042 Rennes Cedex, France.

"Corresponding author;

Email: lafage.denis@gmail.com 


\section{Abstract}

A large number of studies have tried to understand the determinants of local species richness, i.e. $\alpha$ diversity. Studies dealing with $\beta$-diversity are considerably less numerous but their number has increased in the recent years.

In this study, we assessed the relative importance of local and landscape (i.e. composition and connectivity) variables in explaining $\alpha$ - and $\beta$-diversities (species turnover and nestedness) of three highly diverse groups, differing in mobility and dispersal: plants, spiders, and carabids. Sampling took place in 2013, using suction samplers for arthropods and phytosociological relevés for vegetation, in 77 hay meadows distributed along $200 \mathrm{~km}$ of the Loire Valley (France).

We found plant $\alpha$-diversity to be driven by local factors, whereas spider and carabid $\alpha$-diversities were mostly determined by landscape factors (by composition and connectivity, respectively). Nestedness was negligible for the three groups. Plant $\beta$-diversity was also mainly influenced by local factors, whereas spider $\beta$-diversity was driven by landscape factors (composition and connectivity, equally). Surprisingly, carabid $\beta$-diversity was mainly influenced by local factors and landscape connectivity. Despite these differences, plant, spider, and carabid $\beta$-diversities were not different, suggesting comparable dispersal abilities and/or a low connectivity at large scale, which is in accordance with the high species turnover observed here. Managing biodiversity in meadows consequently necessitates acting at local and landscape scales, the first targeting plants and the second arthropods.

\section{Key words: connectivity; variance partitioning; nestedness; spiders; carabids}




\section{Introduction}

A large number of studies have tried to understand the determinants of local species richness, i.e. $\alpha$ diversity (Jiménez-Valverde et al. 2010). Studies dealing with $\beta$-diversity are considerably less numerous (McKnight et al. 2007) but their number has increased in the recent years (e.g. Hendrickx et al. 2007; Boieiro et al. 2013; Braaker et al. 2013). $\alpha$-Diversity describes within-habitat diversity (MacArthur and Wilson 1967) and is mainly driven by local processes (Whittaker 1972). $\beta$-Diversity, or between-habitat diversity (Magurran 2004) is believed to respond to two models: i) the niche model, which states that species sorting is linked to species requirements; ii) the model which states that species sorting is linked to dispersal across the landscape (Nekola and White 1999). Thus $\beta$-diversity is generally thought to be driven by both local and landscape factors, yet the impact of local and landscape factors on $\alpha$ - and $\beta$ diversities seems to vary among groups (e.g. Báldi et al. 2013; Duflot et al. 2014) and habitats studied (e.g. Jeanneret et al. 2003a). For instance, plant species richness response to landscape diversity has been found to be negative by Roschewitz et al. (2005), positive by Weibull et al. (2003) and null by Dauber et al. (2003) and Krauss et al. (2004). It is generally hard to draw a precise picture of the factors shaping diversity, and especially $\beta$-diversity, of diverse groups at different scales because most studies either investigated one model-group or used different explanatory variables in diverse habitats, making hard to properly compare the influence of similar variables on different taxa.

In agro-ecosystems, meadows are considered to be the most species-rich habitat (Noordijk et al. 2010; Woodcock et al. 2011) and have been proven to be an important source of diversity for crops (Benton et al. 2003; Purtauf et al. 2005). Plants and arthropods are a key component of meadow ecosystems, particularly spider and carabid species that can play a role in pest control (Symondson et al. 2002). However, the intensification of agricultural practices has led to a serious impoverishment of species diversity with the introduction of damaging practices (Marshall et al. 2006) and landscape homogenisation (e.g. Schmidt and Tscharntke 2005; Strijker 2005). In Europe, agri-environment schemes (AES) have been implemented to counteract these effects by providing financial incentives for farmers to adopt extensive agricultural practices. AES seem to have varying success (Kleijn et al. 2006; Lafage and Pétillon 2015) depending on the AES type and the model studied. 
Indeed, some studies recently suggested that landscape factors could have a higher impact on species diversity than management practices (Weibull et al. 2003; Batáry et al. 2008), lowering the effect of agricultural practices improvement. Understanding the relative importance of local and landscape factors on $\alpha$ - and $\beta$-diversities is thus essential to design effective measures to promote biodiversity in agroecosystems. Further, assessing the relative contributions of local versus regional processes is considered essential in understanding global patterns of species diversity (Huston 1999).

Here, using variance partitioning, we disentangled the influence of both local and landscape (composition and connectivity) variables on $\alpha$ - and $\beta$-diversities of three biological model groups varying in (shortdistance) mobility and (long-distance) dispersal: two groups of macro-arthropods (spiders and carabids) and plants in a single habitat, some meadows of the Loire Valley.

Due to the lack of mobility of plants, we first expected $\alpha$-diversity of plants to be more driven by local factors than that of spiders and carabids. In wet meadows, seed dispersal is reported to be low outside of flood events, and we consequently expected $\beta$-diversity of plants to be more determined by local than landscape factors (well-known role of local filters: Keddy 1992), and also to be higher than that of the two other groups (due to increased turnover). Lastly, due to their long-distance dispersal abilities, we expected diversities of spiders and carabids to be mostly driven by landscape factors, but mainly shaped by landscape connectivity for carabids (active dispersal) and by landscape composition for spiders (passive dispersal). The relationship between structuring factors and biological groups was also investigated with an explanatory approach using multivariate analyses of species composition of the three studied taxa.

Due to differing dispersion abilities and mobility, we expected the relative importance of local and landscape factors to differ among groups, especially regarding $\beta$-diversity. For plants, little is known about the influence of the surrounding landscape and its relative importance (Marini et al. 2008). 
For animals, the ability of individuals to disperse among local communities may be an important determinant of species turnover and nestedness, where species with low dispersal ability are strongly influenced by increasing habitat isolation (Hendrickx et al. 2009). Thus, we expected spider and carabid $\beta$-diversities to be mainly influenced by landscape connectivity, and plant $\beta$-diversity by local conditions. Indeed, Weibull et al. (2003) found species richness of butterflies, carabids, rove beetles, and spiders to generally increase with landscape heterogeneity on a farm scale. On the other hand, Öberg et al. (2007) found Linyphiidae (a spider family) diversity to be more sensitive to local habitat type. Finally, due to differences in dispersal capacities, we expected spider and carabid $\beta$-diversities to be lower than plant $\beta$ diversity.

\section{Methods}

Study area and sampling design

The study site covered $200 \mathrm{~km}$ of the Loire Valley in Western France (Figure 1). Land is mainly covered by hay meadows and poplar groves. The hedgerow network is prominent. Hay meadows are cut in early or mid-summer and usually grazed by cattle in autumn.

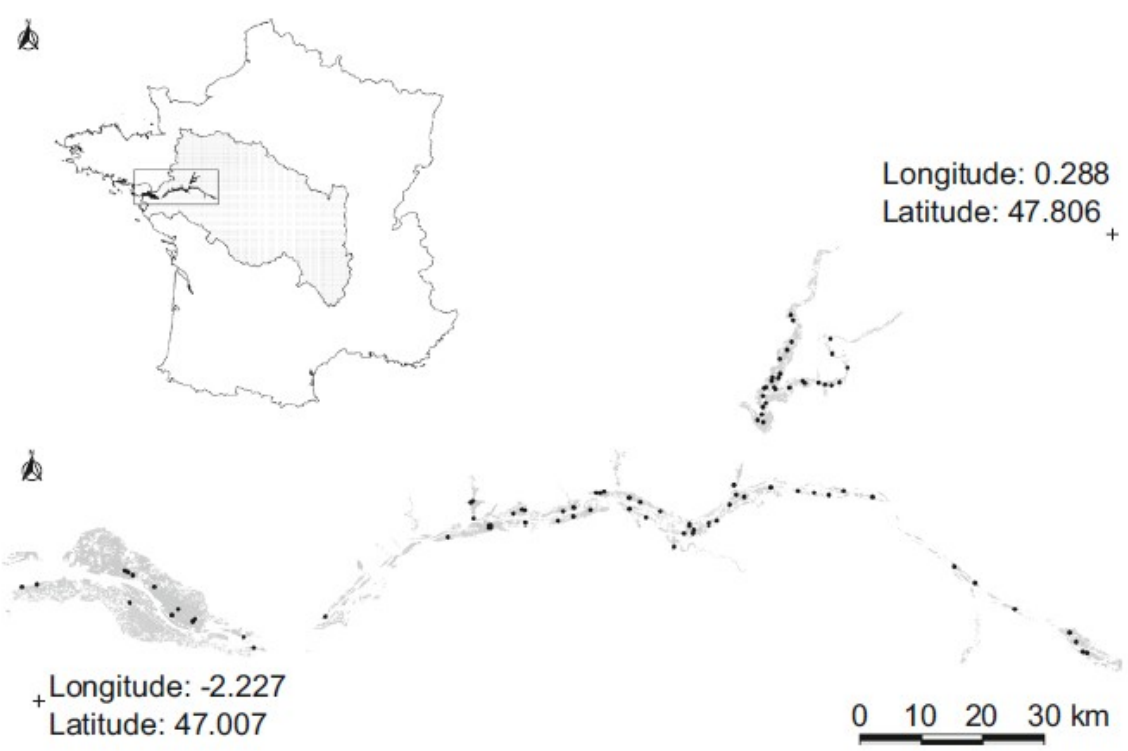

Fig. 1 Localisation of the study sites in the Loire watershed (France). Grey mesh surfaces in the France map represent the Loire river watershed. Grey mesh surfaces indicate meadows and black dots correspond to the sampled meadows 
Carabids and spiders were sampled in 77 hay meadows along the study area. Sampling was carried out on 1-28 June 2013, between 10.00 and 17.00, when weather was dry. Suction sampling was realised using a suction sampler with a $12.5-\mathrm{cm}$ diameter intake placed on the ground. At each sampling site, 5 samples were taken. Each sample consisted of 10-15-s suctions (total area: $0.12 \mathrm{~m}^{2} / \mathrm{sample}$ ). Samples were stored in $70 \%$ alcohol in the field and taken back to the laboratory for sorting and identification to species level. Suction sampling is a standard technique to provide quantitative data (Brook et al. 2008).

One plant survey per site was performed from May to June 2013. Each relevé survey sampled homogeneous herbaceous vegetation in a $16-\mathrm{m}^{2}$ plot (Chytrý and Otypkova 2003). Within each plot, a cover value (6 classes: $<1 \% ; 1-5 \% ; 5-25 \% ; 25-50 \% ; 50-75 \% ; 75-100 \%$ ) was attributed to each plant species.

Environmental characteristics

Three variable sets likely to affect arthropod and plant diversities were defined. The first variable set comprised eight variables describing local conditions. Two variables relevant for spiders and carabids described habitat conditions determined by vegetation: mean litter depth (ten measurements, to the next $\mathrm{cm}$, per sampling plot) and mean vegetation height (ten measurements, to the next $\mathrm{cm}$, per sampling plot). Soil characteristics were defined using mean Ellenberg indicator values (Ellenberg et al. 1992) for moisture, nutrient level, and exposure to light. One factor described whether the site had been flooded during spring 2013 (i.e. a binary variable for the short-term effects of flooding) as flooding has been proven to have a strong impact on carabid and spider assemblages (Lafage et al. 2015). Two variables described local meteorological conditions (mean temperature and precipitation during the sampling month).

The second set of variables corresponded to landscape composition regarding land-cover and geology. It included the four dominant land-cover types (grasslands, woods, water, and urbanisation) defined at four different scales, using buffers. 
Given the landscape configuration, buffers were limited to $400 \mathrm{~m}$ to avoid including hills or too large amounts of water surface (buffers: 100, 200, 300, and $400 \mathrm{~m}$ ). It also included bedrock type (arena, granite, gneiss, mica, clay, shale, chalk). Land cover types and hedgerows (see after) were retrieved using photo-interpretation of satellite imagery (BD Ortho IGN, 2008 and 200il9) (Vaudelet 2008). We retrieved bedrock type from the Simplified Lithographic Map provided by the 'Bureau de Recherches Géologiques et Minières' (BRGM).

The third variable set characterised connectivity. It included three variables describing meadows localisation: distance to the sea (longitudinal connectivity), minimum distance to the river Loire (lateral connectivity), and distance to a hedgerow. Longitudinal and lateral connectivity were included because of their role in shaping plant and arthropod distribution (Johanson et al. 1996; Bonn et al. 2002). It also included landscape heterogeneity, estimated using the Landscape Shannon Diversity Index (SHDI), using the same four buffers used for the landscape data set. SHDI was calculated using the QGIS plugin LecoS (Jung 2012). Landscape closure was estimated using the beta index (BI) of connectivity (beta = number of hedges/number of nodes). Area of the field was also included in this dataset. Correlations between predictive variables of each set were tested using Pearson tests but were weak or not significant (Table S1, S2 and S3). Finally, variables describing spatial patterns in arthropod communities at different scales were researched. We used Moran's eigenvector maps (MEM) (Legendre et al. 2013); see Braaker et al. (2013) for a detailed description.

Statistical analyses

Spider and carabid species richness ( $\alpha$-diversity) were estimated for each sampling site using the average of four non-parametric estimators based on species incidence: Chao1, Jacknife1, Jacknife2, and Bootstrap. $\beta$-Diversity was estimated through a dissimilarity matrix (corresponding to Sørensen pair-wise dissimilarity) partitioned into its two components — species turnover ( $\beta \mathrm{t})$ and nestedness $(\beta \mathrm{n})$ - following Baselga (2010) and using the betapart R package (Baselga and Orme 2012). 
To ensure the buffer scalefits to group requirements, we performed simple regressions on each variable and selected the radius with lowest AIC value for each land cover or connectivity variable, and each response variable (Table S4).

Variables shaping arthropod and plant $\alpha$-diversities were defined using multiple regressions with a stepwise model selection procedure by AIC (Akaike 1974), implemented in the MASS R package (Venables and Ripley 2002). Linear, logarithmic, inverse, quadratic, cubic, power, compound, logistic, growth, and exponential regression were compared and the model with the highest $\mathrm{R}^{2}$ was selected. Relative contribution of explicative variables to the model was estimated using the relaimpo package (Grömping 2006) with the $\mathrm{R}^{2}$ contribution averaged over orderings among regressors (Lindeman et al. 1980; Chevan and Sutherland 1991).

To test for differences in $\beta$-diversities among groups, multiple-site dissimilarity matrices were computed using the betapart package for R (Baselga and Orme 2012) and the Simpson dissimilarity index. We then performed a re-sampling procedure in the $\beta$-diversity matrix ( 50 pairs of sites were randomly sampled 50 times) to perform multiple comparison tests.

To identify variables significantly explaining arthropod and plant $\beta$-diversities, similarity matrices corresponding to species turnover were regressed against environmental variables using the Canonical Analysis of Principal Coordinates (CAP) implemented in the vegan package for R (Oksanen et al. 2013). The environmental model was built with a forward selection procedure, using CAP, on the environmental dataset to select significant variables ( $P=0.05$ after 9999 random permutations) to explain variation in dissimilarity matrices. Variance partitioning was then performed on the selected variables using the vegan package. Variables expressed in proportion (land cover) were arcsine-transformed and surface variables were log-transformed to fit with normal distribution.

To investigate possible differences between groups, spider, carabid, and plant drivers of species assemblages were investigated using constrained analysis. Following Legendre and Gallagher (2001), species activity-densities were transformed to a Bray-Curtis distance matrix prior to analyses. 
The choice between redundancy analysis (RDA) and constrained correspondence analysis (CCA) was made according to the axis length of a detrended correspondence analysis (DCA). In the analyses, the distance matrix was the response variable and the environmental variables were the predictors. Monte Carlo tests with 999 permutations were carried out to test the significance of the selected environmental factors and constrained analyses axes.

\section{Results}

A total of 6036 spiders belonging to 97 species, 383 carabids belonging to 43 species, and 181 plant species were sampled. Spider and carabid assemblages were dominated by small aerial dispersers: $78 \%$ of spiders were Linyphiidae and $78 \%$ of carabids were small winged species. Spider assemblages were dominated by six Linyphiid species Tenuiphantes tenuis (29.4\% of individuals), Meioneta rurestris (7.0\% of individuals), Erigone dentipalplis (4.8\%), Bathyphantes gracilis (4.8\%), Oedothorax fuscus (4.4\%) and Meioneta mollis (4.2\%). Carabid assemblages were dominated by two Harpalin species (Acupalpus exiguus: $51.0 \%$ and Syntomus obscuroguttatus: 15.4\%) and one Bembidin species (Bembidion biguttatus: 7.8\%). Plant assemblages were more balanced with ten species totalising a cumulative cover of $35 \%$, with a frequency ranging from $6.1 \%$ (Lolium perenne) to $2.3 \%$ (Plantago lanceolata).

The MEM analysis did not reveal any significant spatial pattern in the spider $(\mathrm{P}=0.15)$, carabid $(P=$ $0.68)$ or plant $(P=0.242)$ diversities and thus were not included in the connectivity data set.

Variables affecting arthropod and plant $\alpha$-diversities

Overall, our models significantly explained plant, spider and carabid $\alpha$-diversities $\left(\mathrm{R}^{2}=0.63, P<0.001\right.$; $\mathrm{R}^{2}=0.52, P<0.001 ;$ and $\mathrm{R}^{2}=0.30, P<0.001$, respectively).

Local variables explained most $\alpha$-diversity variance in plants (54.90\%, Figure 2$)$. 


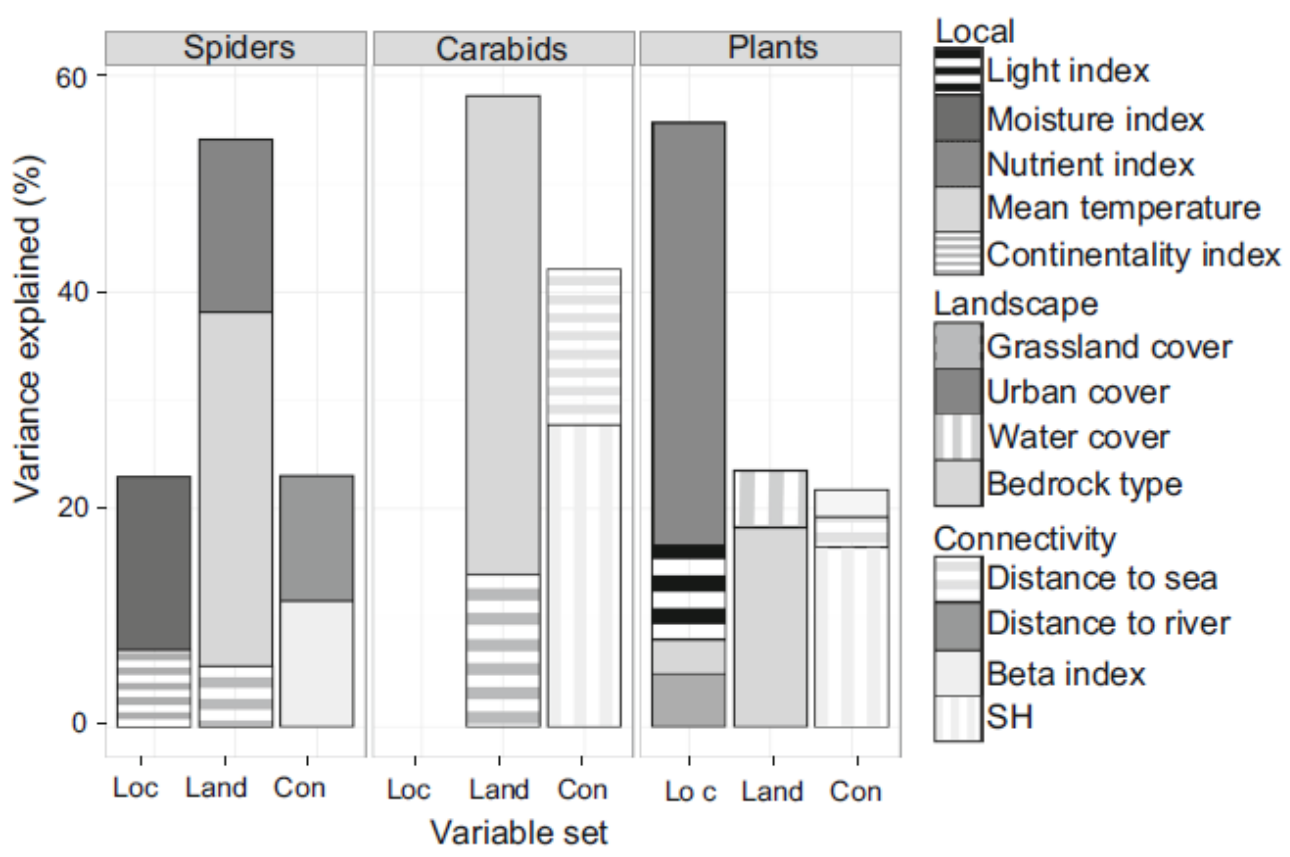

Fig. 2 Relative percentage of variance explained by each variable for spider, carabid and plant $\alpha$-diversity. Loc local, Land landscape, Con connectivity

Mean nutrient index was the main local factor (39.42\% of variance explained) and was negatively linked to $\alpha$-diversity (Table 1). The fraction of spider and carabid $\alpha$-diversities explained by local factors was moderate to null $(22.86 \%$ and $0 \%$, respectively). Spider $\alpha$-diversity was mostly negatively affected by moisture ( $15.8 \%$ of variance explained).

Landscape composition variables were the best predictors of spider and carabid $\alpha$-diversities $(54.09 \%$ and $57.93 \%$ of relative variance explained, respectively; see Figure 2). Bedrock type was the main factor explaining spider, carabid, and plant $\alpha$-diversities $(32.5 \%, 44.01 \%$, and $18.28 \%$ of variance explained, respectively).

Finally, connectivity moderately explained $\alpha$-diversity of spiders and plants $(23.05 \%$, and $21.70 \%$, respectively), with the $\mathrm{BI}$ (beta index of connectivity) being the most important factor positively affecting spider $\alpha$-diversity and negatively affecting plant $\alpha$-diversity. Connectivity explained $42.07 \%$ of relative variance in carabid $\alpha$-diversity, with the BI as the most important factor with a positive effect. 
Spider $\beta$-diversity was 0.97 , corresponding to $\beta \mathrm{t}=0.95$ and $\beta \mathrm{n}=0.02$. Carabid $\beta$-diversity was 0.95 , corresponding to $\beta \mathrm{t}=0.92$ and $\beta \mathrm{n}=0.03$. Plant $\beta$-diversity was 0.96 , corresponding to $\beta \mathrm{t}=0.95 \beta \mathrm{n}=$ 0.01. $\beta \mathrm{n}$ of the three groups was thus considered negligible and was not included in further analysis.

We did not find any significant difference in $\beta$-diversity between the three groups $\left(\chi^{2}=46.34\right.$, df $=47, P$ $=0.499)$.

Table 1 Variables selected by the multiple regression program, stepAIC, for spider, carabid and plant $\alpha$-diversity

\begin{tabular}{|c|c|c|c|c|c|c|c|c|c|}
\hline & \multicolumn{3}{|c|}{ Spiders } & \multicolumn{3}{|c|}{ Carabids } & \multicolumn{3}{|l|}{ Plants } \\
\hline & $F$ & $P$ & Direction & $F$ & $P$ & Direction & $F$ & $P$ & Direction \\
\hline \multicolumn{10}{|l|}{ Local } \\
\hline \multicolumn{10}{|l|}{ Mean vegetaion height } \\
\hline \multicolumn{10}{|l|}{ Litter depth } \\
\hline Mean temperature & 20.54 & $<0.001$ & $-(1)$ & & & & 8.36 & 0.005 & ns \\
\hline Precipitations & & & & 1.78 & 0.187 & & & & \\
\hline Mean moisture index & 13.95 & $<0.001$ & $-(\mathrm{c})$ & 2.14 & 0.149 & & & & \\
\hline Mean continentality index & 2.20 & 0.143 & & & & & 11.59 & $<0.001$ & $-(q)$ \\
\hline Mean light index & & & & & & & 15.94 & $<0.001$ & $+(\mathrm{q})$ \\
\hline Mean nutrient index & & & & & & & 43.66 & $<0.001$ & $-(q)$ \\
\hline Flooding & 0.57 & 0.455 & & 1.48 & 0.229 & & 1.87 & 0.176 & \\
\hline \multicolumn{10}{|l|}{ Landscape } \\
\hline Grassland cover & 5.17 & 0.026 & $-(\mathrm{L})$ & 5.86 & 0.019 & $-(1)$ & & & \\
\hline Urban cover & 10.54 & 0.002 & $+(\mathrm{L})$ & & & & & & \\
\hline Water cover & & & & 2.36 & 0.129 & & 4.64 & 0.036 & $+(q)$ \\
\hline Wood cover & 1.59 & 0.212 & & & & & & & \\
\hline Lithography & 4.25 & $<0.001$ & & 2.43 & 0.036 & & 2.89 & 0.015 & \\
\hline Area & & & & 0.65 & 0.424 & & & & \\
\hline \multicolumn{10}{|l|}{ Connectivity } \\
\hline Distance to the sea & & & & 4.37 & 0.041 & ns & 5.25 & 0.026 & ns \\
\hline Distance to the river & 9.96 & 0.002 & $-(\mathrm{p})$ & 0.78 & 0.381 & & 3.86 & 0.054 & \\
\hline Min distance to hedge & & & & & & & 0.05 & 0.822 & \\
\hline Beta index of connectivity & 7.37 & 0.009 & $+(\mathrm{L})$ & 13.42 & $<0.001$ & $+(\mathrm{L})$ & 22.54 & $<0.001$ & $-(1)$ \\
\hline Index of heterogeneity & & & & & & & 13.24 & $<0.001$ & ns \\
\hline
\end{tabular}

$F$ and $P$ values are given only for the variables kept in the model by AIC. Direction corresponds to global trends of the best model fitting each variable to $\alpha$-diversity. Letters in bracket indicate best model type $(l \log , c$ cubic, $L$ linear, $p$ power, $q$ quadratic, $n s$ no significant)

Variables affecting arthropod and plant $\beta$-diversities

The first nine axes of the CAP on plant $\beta$-diversity were significant and explained $51.43 \%$ of species turnover. The first four axes of the CAP on spider $\beta$-diversity were significant and explained $20.55 \%$ of species turnover. The first three axes of the CAP on carabid $\beta$-diversity were significant and explained $31.46 \%$ of species turnover.

Variance partitioning revealed that local factors mainly affected plant $\beta$-diversity $(43.75 \%$ of relative variance, Figure 3). Plant $\beta$-diversity was negatively affected by precipitation, by all Ellenberg indicators tested, and by flooding (Table 2). 


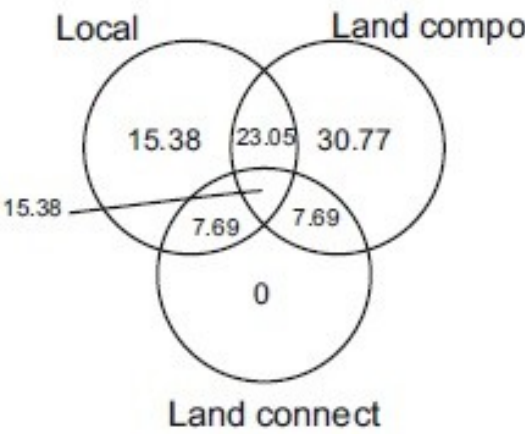

Spiders

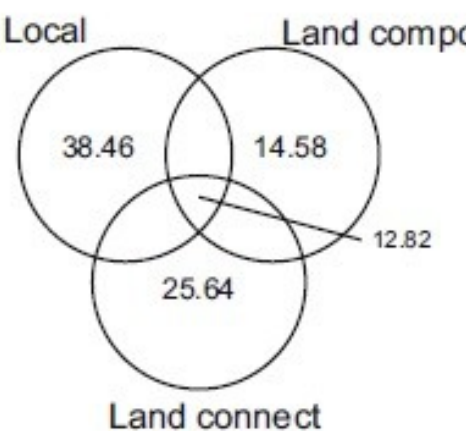

Carabids

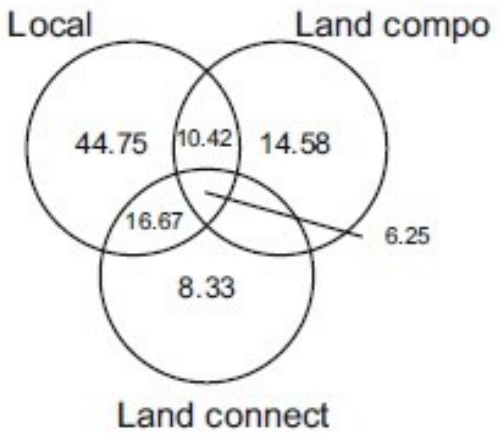

Plants

Fig. 3 Venn diagram for variance partitioning of spider, carabid, and plant b-diversity. Values correspond to relative variance explained

(non-significant values were not shown). Land compo landscape composition, land connect landscape connectivity

Table 2 Variables selected by|the forward selection after canonical analysis of principal coordinates (CAP) on the $\beta$-diversity matrix for spiders, carabids, and plants

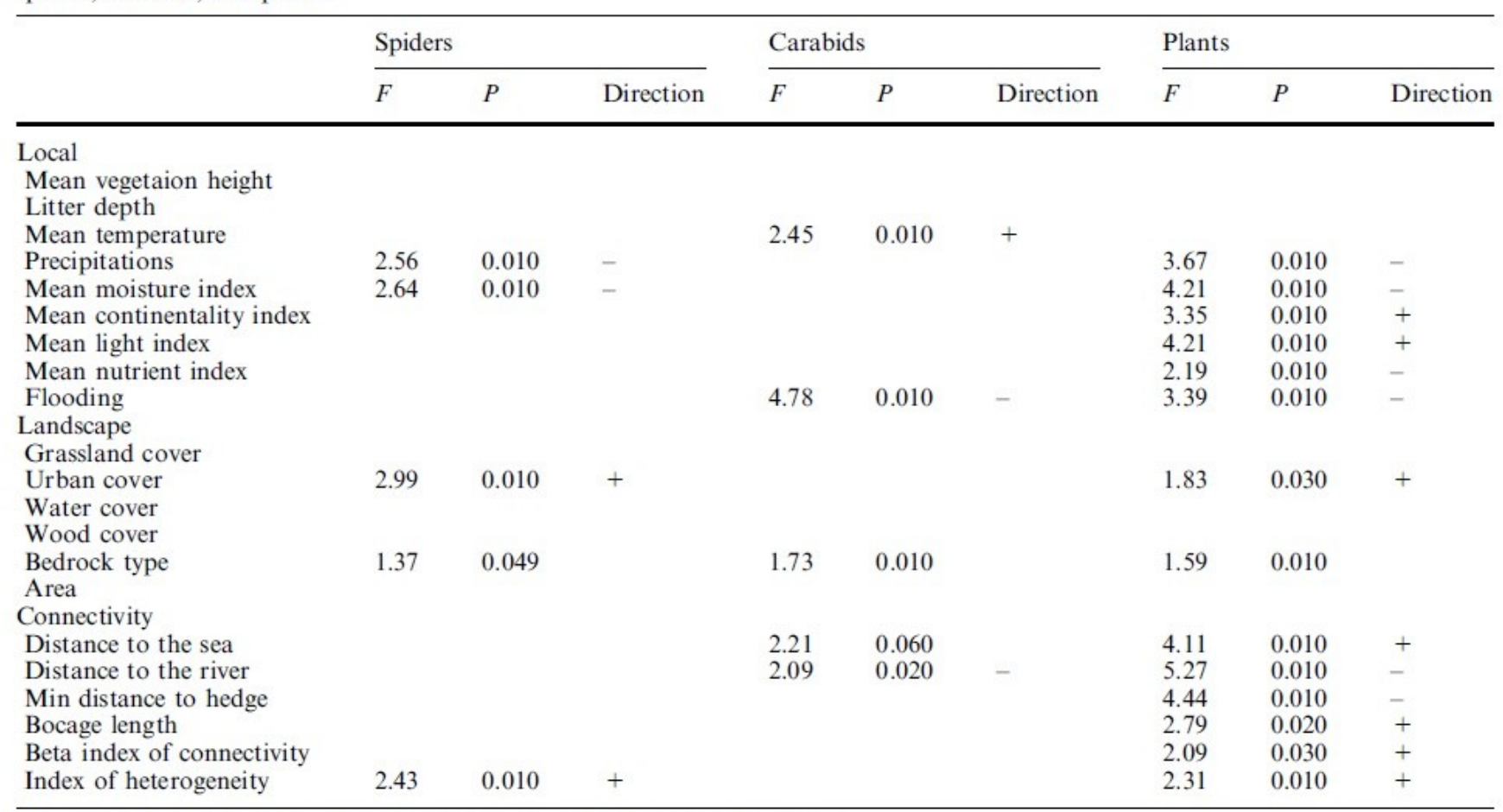

$F$ and $P$ values are given only for the variables kept in the model by AIC

Spider $\beta$-diversity was mainly affected by landscape composition variables $(30.77 \%$ of relative variance,

Figure 3), and was positively determined by urban cover and by bedrock type (Table 2). When including interactions with local and landscape composition variables, connectivity was the second driver of spider $\beta$-diversity (30.76\% of relative variance). Landscape heterogeneity also positively influenced spider $\beta$ diversity (Table 2).

Carabid $\beta$-diversity was influenced by local factors $(38.46 \%$ of variance explained) and positively determined by mean temperature. 
When including interactions with local and landscape composition variables, connectivity was the second driver of carabid $\beta$-diversity (38.46\% of relative variance). Distance to the river negatively influenced carabid $\beta$-diversity (Table 2).

Variables determining species assemblage composition

CCA on spider assemblages explained $42.9 \%$ of the total variance, with the first three axes of the CCA significant (all with $P=0.005$ ). Variables explaining spider species composition were mainly moisture and distance to nearest hedge and bedrock type (Figure 4).

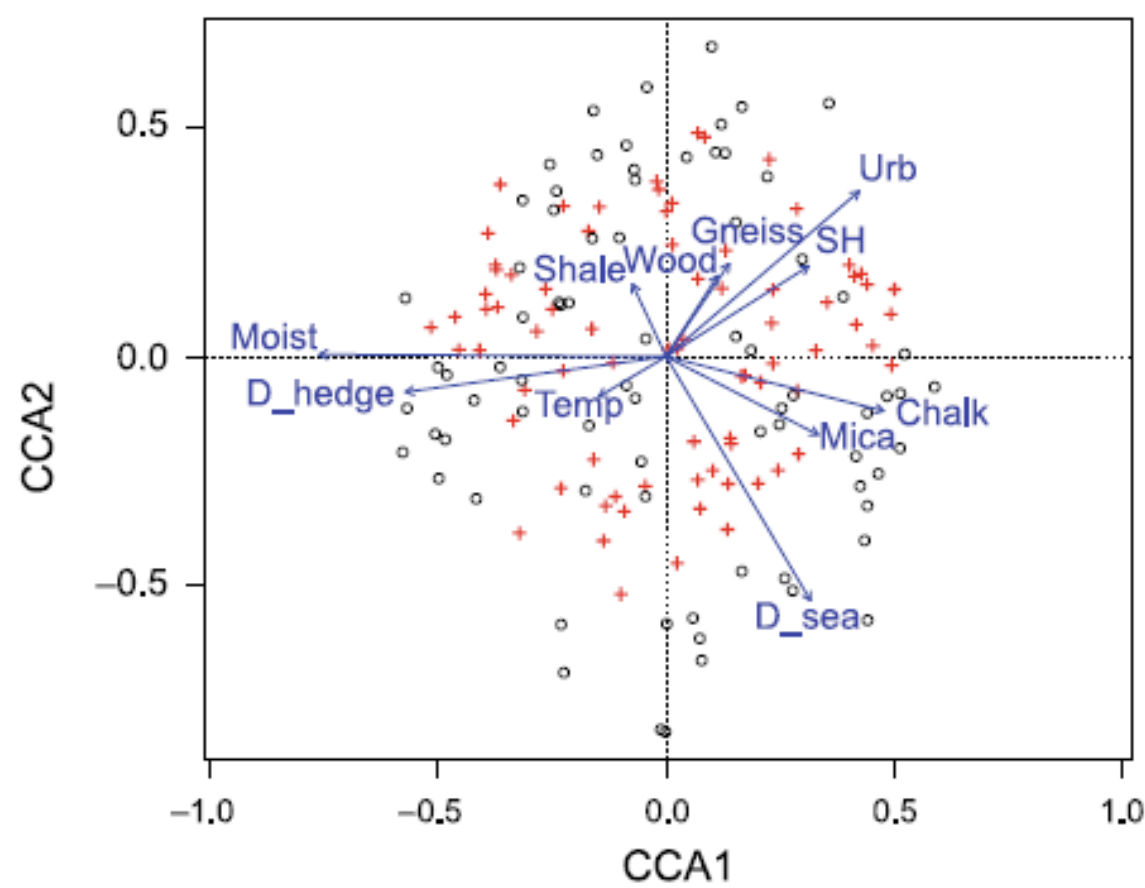

Fig. 4 Projection of significant variables from the CCA on spider species' Bray-Curtis distances. Sites are represented by crosses, and species by circles. Urb \% urbanisation, Wood $\%$ woodland, D_sea distance to sea, Temp mean temperature, D_hedge distance to the nearest hedge, Moist Ellenberg index of moisture

RDA on carabid assemblages explained $57.59 \%$ of total variance, with the first two axes of the RDA significant $(P=0.051$ and $P=0.024$, respectively). The main variables explaining carabid species composition were flooding, moisture, and distance to nearest hedge (Figure 5). 


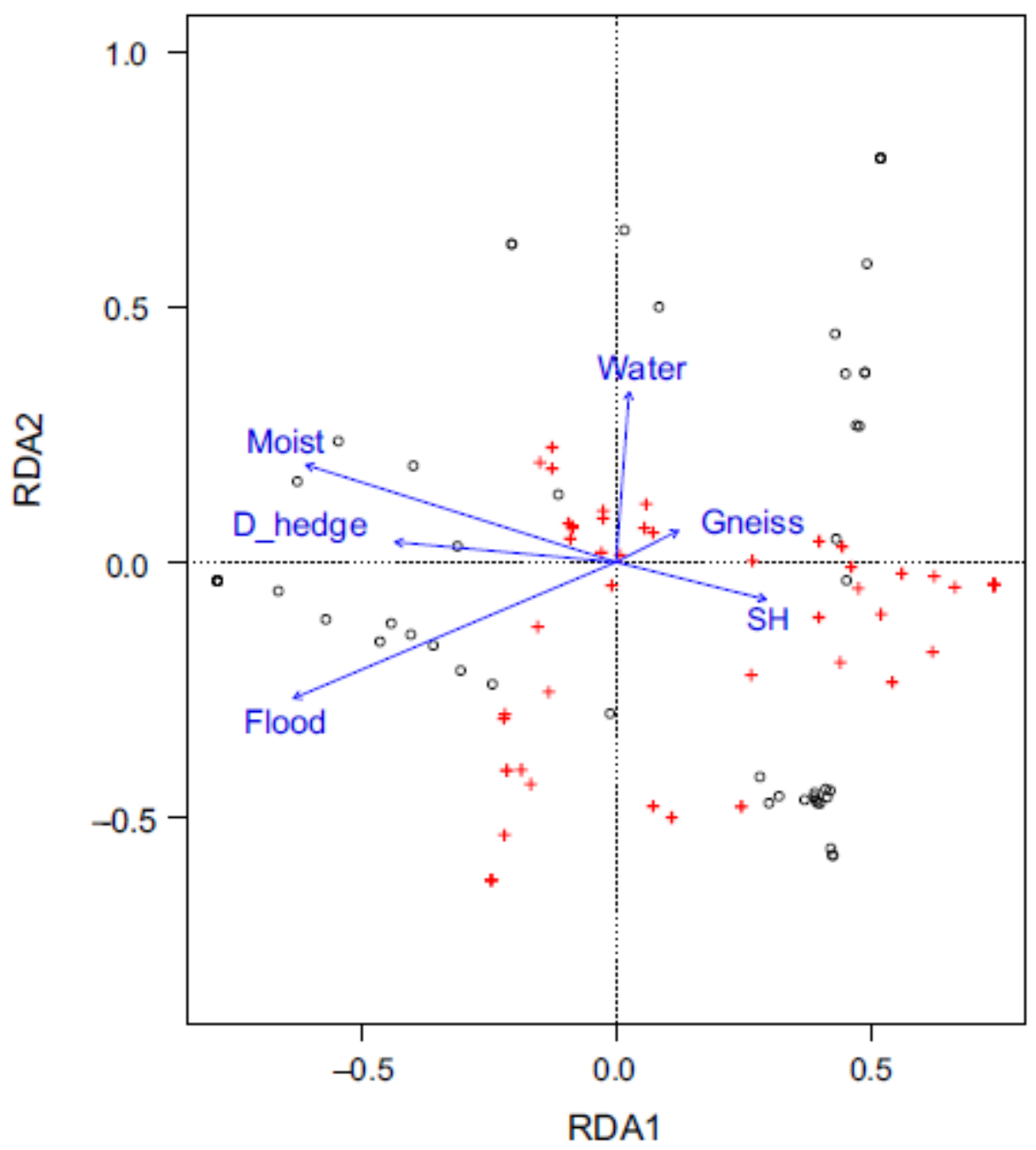

Fig. 5 Projection of significant variables from the RDA on carabid species' Bray-Curtis distances. Sites are represented by crosses, and species by circles. D_hedge distance to the nearest hedge, Moist Ellenberg index of moisture, $\mathrm{SH}$ heterogeneity index, Water $\%$ water, Flood site flooded or not

RDA on plant assemblages explained $54.8 \%$ of total variance, with the first six axes significant $(P=$ $0.005, P=0.005, P=0.005, P=0.005, P=0.01, P=0.013$, respectively). Main variables explaining plant species composition were moisture, nutrient, distance to the river, and distance to the nearest hedge (Figure 6). 


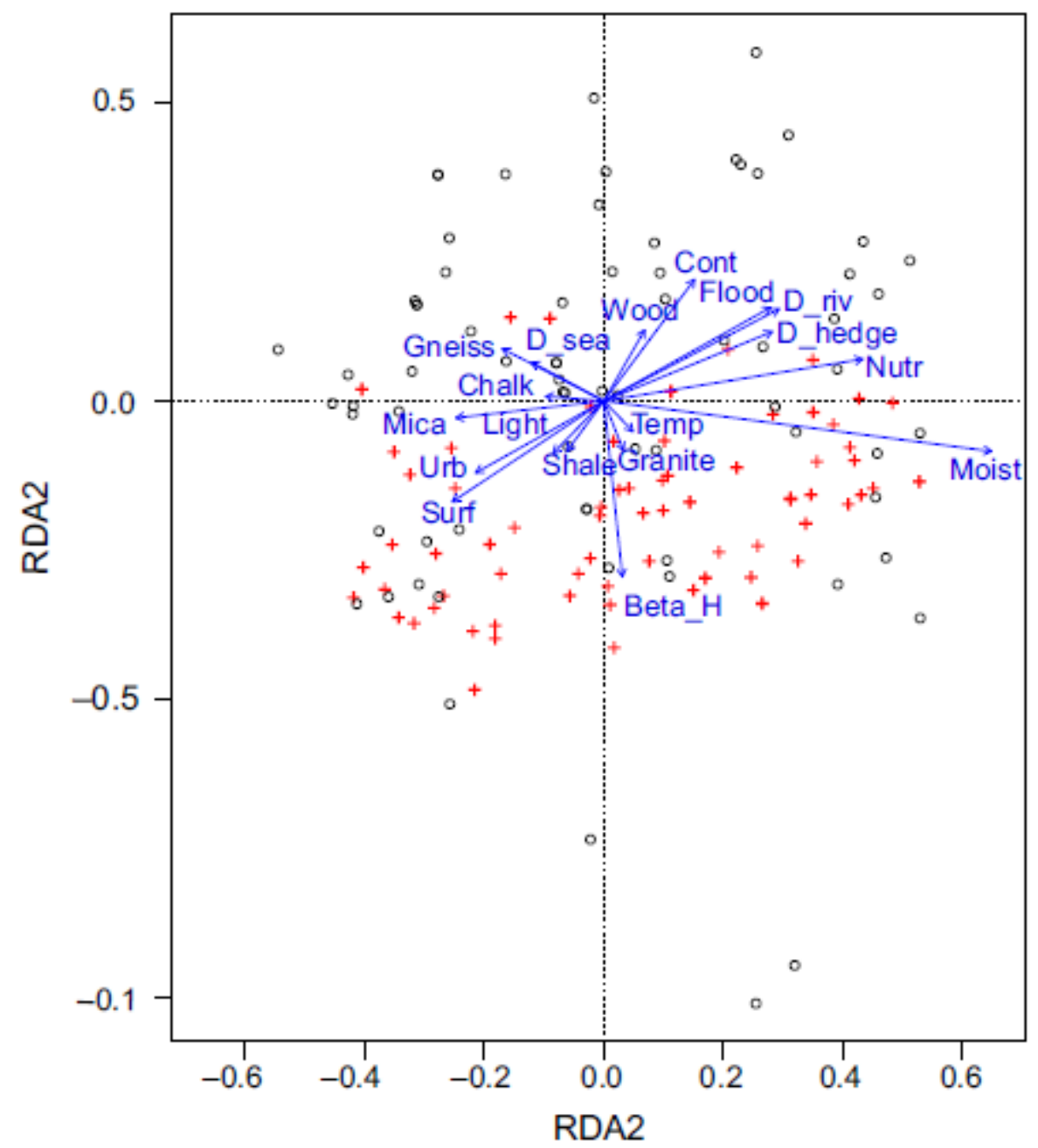

Fig. 6 Projection of significant variables from the RDA on plant species' Bray-Curtis distances. Sites are represented by crosses, and species by circles. Wood \% woodland, Cont Ellenberg index of continentality, D_riv distance to the Loire River, D_hedge distance to the nearest hedge, Nutr Ellenberg index of nutrient, Moist Ellenberg index of moisture, Temp mean temperature, beta_H heterogeneity index, Surf surface, Urb \% urbanisation, Light Ellenberg index of light, D_sea distance to the sea, Flood site flooded or not

\section{Discussion}

By comparing different groups in a same habitat, our study demonstrated that local factors better explained plant $\alpha$-diversity, whereas spider and carabid $\alpha$-diversities were more determined by landscape factors (composition and connectivity) in a floodplain. Nevertheless, variables affecting species assemblages were quite similar for the three groups and consistently included soil moisture and distance to the nearest hedge. 
Plant $\alpha$-diversity was primarily explained by soil nutrient index. This is in accordance with the numerous studies demonstrating that soil enrichment negatively influences plant $\alpha$-diversity (e.g. Grace 1999). Furthermore, local characteristics such as abiotic environment (Sebastia 2004; Bennie et al. 2006) and other soil characteristics (Critchley et al. 2002) have been demonstrated to influence plant species richness.

Among local variables, spider $\alpha$-diversity was most sensitive to the moisture index. This is also in accordance with numerous studies demonstrating that soil moisture is an important driver of spider assemblages (Entling et al. 2007; Pétillon et al. 2008). In floodplains with regular flooding events, the Ellenberg index of moisture reflects the flood duration that is known to have negative effects on arthropod species richness (e.g. Guerish et al. 2012).

Spider and carabid $\alpha$-diversities were best explained by landscape composition. $\alpha$-Diversity of the two groups was mainly affected by bedrock type. In floodplains, bedrock type influence soil moisture, granulometry and nutrient content, which in turn affects arthropods and plants. Arthropod diversity is indeed negatively affected by flooding (Guerish et al. 2012), carabid diversity is affected by soil structure because of their edaphic larval phase (Blake et al. 2003), and plant diversity is negatively affected by nutrient content (Grace 1999). Nevertheless, our findings for spiders were in opposition to previous studies, which did not find any influence of bedrock type on spider communities (Coulson and Butterfield 1986; Sanderson et al. 1995). In intensive agro-ecosystems, landscape composition is usually considered a limiting factor for spider species richness (Benton et al. 2003; Purtauf et al. 2005). Conversely, in a landscape extensively dominated by hay meadows, we found spider diversity being positively affected by urban cover, although to a lesser extent. Sites with highest urban covers presented a high number of unique singleton that appear to be species associated with dry meadows. In floodplains, urbanisation takes place in zones excluded from flooding. Thus, the apparent positive influence of urbanisation could be explained by the highest altitude of urbanized zones.

As a large part of spider assemblage was composed by Linyphiidae (78\% of individuals), which passively disperses through ballooning, it follows that ubiquitous species usually found in urbanised zones could have successfully colonised meadows. 
Landscape effect on spider diversity is still under debate as it may depend on the habitat under study (Jeanneret et al. 2003a). For instance, Batáry et al. (2008) found no impact of landscape on spider richness in Hungarian pasture, whereas other studies have positively demonstrated its effect on species richness in crop fields, fallow lands, and woodlots (Schmidt and Tscharntke 2005 ; Schmidt et al. 2005 ; Öberg et al. 2007 ; Drapela et al. 2008).

Carabids are usually considered more sensitive to landscape than spiders (e.g Jeanneret et al. 2003b). However, our results suggest that spider $\alpha$-diversity is more influenced by landscape composition, whereas carabid $\alpha$-diversity is more influence by landscape connectivity, which was also suggested in a spider-carabid comparative study (Barabaro et al. 2005). For the three groups, the beta index of connectivity was the main variable affecting species diversity, among the connectivity variables tested. This index, reflecting the landscape's enclosure by a hedgerow network, was expected to have a positive impact on arthropod and plant $\alpha$-diversities by allowing the presence of woody species and facilitation of movements between suitable habitats (Burel 1989; Weibull et al. 2003; Purtauf et al. 2005; Miyashita et al. 2012). In this instance, our hypotheses were confirmed for spiders and carabids but not for plants. This might be a result of a limited capacity of woody plants to colonise grasslands. For instance, Łukasz and Sadowska (1997) found an optimum diversity $3 \mathrm{~m}$ away from the edge between forest and grassland.

We also observed that Linyphiidae and Harpalini dominated the assemblages of spiders and carabids respectively. This dominance of small species could first be attributed to a sampling effect, although suction sampling is usually recommended to quickly obtain a representative sample of epigeic arthropod communities (e.g. Duffey 1974). In fact, Mommertz et al. (1996) considered it an inefficient way to sample large arthropods (such as Carabidae and Lycosidae). However, Brook et al. (2008) considered suction sampling an efficient technique to sample arthropods, including Carabidae, pending a sufficient sampling effort. We can thus consider that our results were not biased by the sampling technique, and that the dominance of small aerial dispersers was a consequence of an environmental filter, here the stochasticity due to flooding (Zulka 1994). 
In our study, the $\beta$-diversity link to nestedness was very weak for the three groups, and contrary to our expectations, we did not find any difference in species turnover rate between the three groups. Interestingly, the main driver of plant, spider, and carabid species assemblages was linked to hydrological conditions (moisture and flooding). This could induce similar $\beta$-diversities of the three groups, with such an important driver acting on assemblages in the same way. In addition, the importance of species turnover suggests either low landscape connectivity for the groups studied, or similar dispersion capacities of the three groups in this particular landscape. Considering the well-known (long-distance) dispersal abilities of plants (Soons et al. 2004), spiders (Bell et al. 2005) and carabids (Kotze \& O'Hara 2003), which have also been reported in alluvial meadows, we argue that they were not limiting, and that the high turnover is more likely explained by weak landscape connectivity. Here, the distance to the nearest hedge was indeed one of the main factors influencing species assemblages of the three groups. Whereas the hedgerow network could be considered a movement facilitator for some animals (Beier and Noss 1998), it can also act as a physical barrier for dispersal (Larrivée and Buddle 2009), especially of ballooning spiders (which represent $78 \%$ of individuals cached) and small carabids $(85 \%$ of individuals cached) as demonstrated in the Loire valley by Lafage et al. (in press). Interestingly plant species assemblages were also driven by the distance from the meadow to the Loire river, suggesting the occurence of hydrochory. In any case, as we only sampled hay meadows, we did not expect a high level of nestedness in $\beta$-diversity. Given the very low contribution of nestedness in total $\beta$-diversity, we chose not to include nestedness in further analysis. This decision was also motivated by the ongoing debate on $\beta$-diversity partitioning. Indeed, Almeida-Neto et al. (2011) suggested that only species turnover estimated by Baselga (2010) is usable.

Species turnover was mainly influenced by local factors for carabids and plants. As expected, local abiotic conditions (assessed by Ellenberg indicator values) explained plant $\beta$-diversity, with moisture as the dominant factor. Logically, mean precipitation and flooding were also variables negatively affecting plant $\beta$-diversity. Among local variables, carabid $\beta$-diversity was only affected by mean temperature, which is in accordance with previous studies (e.g. Gillingham et al. 2012). 
Among landscape composition variables, bedrock type influenced all group $\beta$-diversities. Nevertheless, spiders were the most sensitive group to landscape composition, including urbanisation, which had a positive effect on species turnover. This is in agreement with the numerous studies which have found bedrock type to be an important driver of arthropod and plant species turnover (carabids: Blake et al. 2003; spiders: Churchill 1998; plants: Janssens et al. 1998; Gabriel et al. 2006).

As expected, connectivity was an important driver of carabid and spider $\beta$-diversity. Indeed, landscape openness is considered a dispersal trait filter for carabids, with highly mobile (small, macropterous) carabid species selected with increasing connectivity (Duflot et al. 2014). As previous studies found ballooning behaviour to be dependent of landscape heterogeneity (Bonte et al. 2006), we expected spider $\beta$-diversity to be positively influenced by landscape heterogeneity. Pure connectivity variables did not explain a significant portion of spider $\beta$-diversity. Nevertheless, interactions between the BI and local and/or landscape variables explained an important part of spider $\beta$-diversity, confirming the results of Bonte et al. (2006). Our findings are also in accordance with Jonsen and Fahrig, (1997) which found generalist insect diversity to increase with habitat diversity.

Overall, spider diversity appeared more sensitive to landscape composition, carabid diversity to landscape connectivity, and plant diversity to local factors. Thus, managing biodiversity in meadows implies acting at both the local and landscape scales, the former with an eye toward plants, and the latter toward arthropods. However, managers have to be aware that improving connectivity through hedgerow networks could also be a brake to biodiversity enhancement, as we found it could be for spiders and carabids. 


\section{Acknowledgments}

We would like to thank the CORELA for its support,Charlotte Papin and Thomas Joubin for field and laboratory assistance, Arnaud Horellou for his help in identifying problematic carabids and Editage for editing the English. This study was funded by 'Plan Loire Grandeur Nature' (FEDER), 'Région Pays de la Loire' and 'Agence de l'Eau Loire-Bretagne'.

\section{Conflict of interest}

The authors declare that they have no competing interests.

\section{Ethical approval}

The authors declare that all appropriate ethics and approvals were obtained for the study. 


\section{References}

Akaike H (1974) A new look at the statistical model identification. IEEE Trans Automat Contr 19:716723.

Almeida-Neto M, Frensel D, Ulrich W (2011) Rethinking the relationship between nestedness and beta diversity: a comment on Baselga (2010). Glob Ecol Biogeogr 21:772-777.

Báldi A, Batáry P, Kleijn D (2013) Effects of grazing and biogeographic regions on grassland biodiversity in Hungary - analysing assemblages of 1200 species. Agric Ecosyst Environ 166:2834. doi: 10.1016/j.agee.2012.03.005

Barbaro L, Guyon D, Jactel H (2005) Comparative responses of bird, carabid, and spider assemblages to stand and landscape diversity in maritime pine plantation forests. Ecoscience 12:110-121. http://dx.doi.org/10.2980/i1195-6860-12-1-110.1

Baselga A (2010) Partitioning the turnover and nestedness components of beta diversity. Glob Ecol Biogeogr 19:134-143. doi: 10.1111/j.1466-8238.2009.00490.x

Baselga A, Orme CDL (2012) betapart : an R package for the study of beta diversity. Methods Ecol Evol 3:808-812. doi: 10.1111/j.2041-210X.2012.00224.x

Batáry P, Báldi A, Samu F, et al (2008) Are spiders reacting to local or landscape scale effects in Hungarian pastures? Biol Conserv 141:2062-2070. doi: 10.1016/j.biocon.2008.06.002

Beier P, Noss RF (1998) Do habitat corridors provide connectivity. Conserv Biol 12:1241-1252.

Bell JR, Bohan DA, Shaw EM, Weyman GS (2005) Ballooning dispersal using silk: world fauna, phylogenies, genetics and models. Bull Ent Res 95:69-114.

Bennie J, Hill MO, Baxter R, Huntley B (2006) Influence of slope and aspect on long-term vegetation change in British chalk grasslands. J Ecol 94:355-368.

Benton TG, Vickery JA, Wilson JD (2003) Farmland biodiversity: is habitat heterogeneity the key? Trends Ecol Evol 18:182-188. doi: 10.1016/S0169-5347(03)00011-9

Blake S, Mccracken DI, Eyre MD, et al (2003) The relationship between the classification of Scottish ground beetle assemblages (Coleoptera, Carabidae) and the National Vegetation Classification of British plant communities. Ecography (Cop) 5:602-616.

Boieiro M, Carvalho JC, Cardoso P, et al (2013) Spatial factors play a major role as determinants of endemic ground beetle Beta diversity of Madeira island laurisilva. PLoS One 8:1-9. doi: 10.1371/journal.pone.0064591

Bonn A, Hagen K, Wohlgemuth-Von Reiche D (2002). The significance of flood regimes for carabid beetle and spider communities in riparian habitats -a comparison of three major rivers in germany. Riv Res Appl 18:43-64.

Bonte D, Borre JV, Lens L (2006) Geographical variation in wolf spider dispersal behaviour is related to landscape structure. Anim Behav 72:655-662. doi: 10.1016/j.anbehav.2005.11.026

Braaker S, Ghazoul J, Obrist MK, Moretti M (2013) Habitat connectivity shapes urban arthropod communities - the key role of green roofs. Ecology Preprint. 
Brook AJ, Woodcock BA, Sinka M, Vanbergen AJ (2008) Experimental verification of suction sampler capture efficiency in grasslands of differing vegetation height and structure. J Appl Ecol 45:13571363. doi: 10.1111/j.1365-2664.2008.01530.x

Burel FG (1989) Landscape structure effects on carabid beetles spatial patterns in western France. Landsc Ecol 2:215-226. doi: 10.1007/BF00125092

Chevan A, Sutherland M (1991) Hierarchical partitioning. Am Stat 45:90-96.

Churchill TB (1998) Spiders as ecological indicators in the Australian tropics: family distribution patterns along rainfall and grazing gradients. Proceedings of the 17th European Colloquium of Arachnology. Edinburgh, pp 325-330

Chytrý M, Otypkova Z (2003) Plot sizes used for phytosociological sampling of European vegetation. J Veg Sci 14:563-570.

Coulson JC, Butterfield J (1986) The spider communities on peat and upland grasslands In northern England. Ecography (Cop) 9:229-239. doi: 10.1111/j.1600-0587.1986.tb01213.x

Critchley CNR, Chambers BJ, Fowbert JA, et al (2002) Association between lowland grassland plant communities and soil properties. Biol Conserv 105:199-215.

Drapela T, Moser D, G. Zaller J, Frank T (2008) Spider assemblages in winter oilseed rape affected by landscape and site factors. Ecography (Cop) 31:254-262. doi: 10.1111/j.2007.0906-7590.05250.x

Duflot R, Georges R, Ernoult A, et al (2014) Landscape heterogeneity as an ecological filter of species traits. Acta Oecologica 56:19-26. doi: 10.1016/j.actao.2014.01.004

Ellenberg H, Weber HE, Düll R, et al (1992) Zeigerwerte von Pflanzen in Mitteleuropa, 2nd ed. Scr Geobot 18:1-258.

Entling W, Schmidt M, Bacher S, et al (2007) Niche properties of Central European spiders: shading, moisture and the evolution of the habitat niche. Glob Ecol Biogeogr 16:440-448. doi:

10.1111/j.1466-8238.2006.00305.x

Fahrig L (2003) Effects of habitat fragmentation on biodiversity. Annu Rev Ecol Syst 2 34:487-515.

Gabriel D, Roschewitz I, Tscharntke T, Thies C (2006) Beta diversity at different spatial scales: plant communities in organic and conventional agriculture. Ecol Appl 16:2011-21.

Gillingham PK, Palmer SCF, Huntley B, et al (2012) The relative importance of climate and habitat in determining the distributions of species at different spatial scales: a case study with ground beetles in Great Britain. Ecography (Cop) no-no. doi: 10.1111/j.1600-0587.2011.07434.x

Grace JB (1999) The factors controlling species density in herbaceous plant communities: an assessment. Perspect Plant Ecol Evol Syst 2:1-28. doi: 10.1078/1433-8319-00063

Grömping U (2006) Relative Importance for Linear Regression in R: The Package relaimpo. J Stat Softw $17: 1-27$.

Hendrickx F, Maelfait J-P, Desender K, et al (2009) Pervasive effects of dispersal limitation on withinand among-community species richness in agricultural landscapes. Glob Ecol Biogeogr 18:607-616. doi: $10.1111 /$ j.1466-8238.2009.00473.x

Hendrickx F, Maelfait J-P, Van Wingerden W, et al (2007) How landscape structure, land-use intensity and habitat diversity affect components of total arthropod diversity in agricultural landscapes. $\mathrm{J}$ Appl Ecol 44:340-351. doi: 10.1111/j.1365-2664.2006.01270.x 
Huston MA (1999) Local processes and regional patterns: appropriate scales for understanding variation in the diversity of plants and animals. Oikos 86:393-401.

Janssens F, Peeters A, Bakker JP, et al (1998) Relationship between soil chemical factors and grassland diversity. Plant Soil 202:69-78.

Jeanneret P, Schüpbac B, Pfiffner L, Walter T (2003a) Arthropod reaction to landscape and habitat features in agricultural landscapes. Landsc Ecol 18:253-263.

Jeanneret, P., Schupbach B., and Luka H. 2003b. Quantifying the impact of landscape and habitat features on biodiversity in cultivated landscapes. Agric Ecosyst Environ 98:311-320.

Jiménez-Valverde A, Baselga A, Melic A, Txasko N (2010) Climate and regional beta-diversity gradients in spiders: dispersal capacity has nothing to say? Insect Conserv Divers 3:51-60. doi: 10.1111/j.1752-4598.2009.00067.x

Johansson ME, Nilsson C, Nilsson E (1996). Do rivers function as corridors for plant dispersal? J. Veg Sci 7:593-598. http://doi.org/10.2307/3236309

Jonsen ID, Fahrig L (1997) Response of generalist and specialist insect herbivores to landscape spatial structure. Landsc Ecol 12:185-197.

Jung M (2012) LecoS - A QGIS plugin to conduct landscape ecology statistics,.

Keddy PA (1992) Assembly and response rules: two goals for predictive community ecology. J Veg Sci 3:157-164.

Kleijn D, Baquero RA, Clough Y, et al (2006) Mixed biodiversity benefits of agri-environment schemes in five European countries. Ecol Lett 9:243-54; discussion 254-7. doi: 10.1111/j.14610248.2005.00869.x

Kotze DJ \& O'Hara RB (2003) Species decline--but why? Explanations of carabid beetle (Coleoptera, Carabidae) declines in Europe. Oecologia, 135:138-148. http://doi.org/10.1007/s00442-002-1174-3

Lafage D, Papin C, Secondi J, et al (2015) Short term recolonisation by arthropod after a spring flood, with a focus on spiders and carabids. Ecography In press. doi: 10.1002/eco.1606.

Lafage D, Pétillon J (2014) Impact of cutting date on carabids and spiders in a wet meadow. Agric Ecosyst Environ 185:1-8.

Larrivée M, Buddle CM (2009) Diversity of canopy and understorey spiders in north-temperate hardwood forests. Agric For Entomol 11:225-237. doi: 10.1111/j.1461-9563.2008.00421.x

Legendre P, Borcard D, Blanchet FG, Dray S (2013) PCNM: MEM spatial eigenfunction and principal coordinate analyses.

Legendre P, Gallagher E (2001) Ecologically meaningful transformations for ordination of species data. Oecologia 129:271-280. doi: 10.1007/s004420100716

Lindeman RH, Merenda PF, Gold RZ (1980) Introduction to bivariate and multivariate analysis. Scott, Foresman Glenview, IL

Łukasz Ł, Sadowska B (1997) Edge effect in different groups of organisms: vascular plant, bryophyte and fungi species richness across a forest-grassland border. Folia Geobot Phytotaxon 32:343-353.

MacArthur RH, Wilson EO (1967) The theory of island Biogeography. Princeton University Press

Magurran AE (2004) Measuring biological diversity. African J Aquat Sci 29:285-286. doi:

$10.2989 / 16085910409503825$ 
Marini L, Scotton M, Klimek S, Pecile A (2008) Patterns of plant species richness in Alpine hay meadows: Local vs. landscape controls. Basic Appl Ecol 9:365-372. doi: 10.1016/j.baae.2007.06.011

Marshall EJP, West TM, Kleijn D (2006) Impacts of an agri-environment field margin prescription on the flora and fauna of arable farmland in different landscapes. Agric Ecosyst Environ 113:36-44. doi: 10.1016/j.agee.2005.08.036

McKnight MW, White PS, McDonald RI, et al (2007) Putting beta-diversity on the map: broad-scale congruence and coincidence in the extremes. PLoS Biol 5:e272. doi: 10.1371/journal.pbio.0050272

Miyashita T, Chishiki Y, Takagi SR (2012) Landscape heterogeneity at multiple spatial scales enhances spider species richness in an agricultural landscape. Popul Ecol 54:573-581. doi: 10.1007/s10144012-0329-2

Nekola JC, White PS (1999) The distance decay of similarity in biogeography and ecology. J Biogeogr 26:867-878. doi: 10.1046/j.1365-2699.1999.00305.x

Noordijk J, Schaffers AP, Heijerman T, et al (2010) Effects of vegetation management by mowing on ground-dwelling arthropods. Ecol Eng 36:740-750.

Öberg S, Ekbom B, Bommarco R (2007) Influence of habitat type and surrounding landscape on spider diversity in Swedish agroecosystems. Agric Ecosyst Environ 122:211-219. doi:

10.1016/j.agee.2006.12.034

Oksanen J, Blanchet FG, Kindt R, et al (2013) vegan: Community Ecology Package.

Pétillon J, Georges A, Canard A, et al (2008) Influence of abiotic factors on spider and ground beetle communities in different salt-marsh systems. Basic Appl Ecol 9:743-751. doi: 10.1016/j.baae.2007.08.007

Purtauf T, Roschewitz I, Dauber J, et al (2005) Landscape context of organic and conventional farms: Influences on carabid beetle diversity. Agric Ecosyst Environ 108:165-174. doi: 10.1016/j.agee.2005.01.005

Sanderson RA, Rushton SP, Cherril AJ, Byrne JP (1995) Soil, vegetation and space: an analysis of their effects on the invertebrate communities of a moorland in north-east England. J Appl Ecol 32:506518.

Schmidt MH, Tscharntke T (2005) The role of perennial habitats for Central European farmland spiders. Agric Ecosyst Environ 105:235-242. doi: 10.1016/j.agee.2004.03.009

Sebastia MT (2004) Role of topography and soils in grassland structuring at the landscape and community scales. Basic Appl Ecol 5:331-346.

Soons, MB, Gerrit WH., Ran, N, \& Katul, GG (2010) Determinants of long-distance seed dispersal by wind in grasslands. Ecology, 85:3056-3068.

Strijker D (2005) Marginal lands in Europe—causes of decline. Basic Appl Ecol 6:99-106. doi: 10.1016/j.baae.2005.01.001

Symondson WOC, Sunderland KD, Greenstone MH (2002) Can generalist predators be effective biocontrol agents? Annu Rev Entomol 47:561-594.

Vaudelet A (2008) Le val de Loire: Cartographie de l'occupation du sol et du bocage de 2007 et analyses de leurs évolutions depuis 1999.

Venables WN, Ripley BD (2002) Modern Applied Statistics with S, Fourth. Springer, New York 
Weibull A-C, Östman Ö (2003) Species composition in agroecosystems: The effect of landscape, habitat, and farm management. Basic Appl Ecol 361:349-361.

Whittaker RH (1972) Evolution and measurement of species diversity. Taxon 21:213-251.

Woodcock BA, Westbury DB, Brook AJ, et al (2011) Effects of seed addition on beetle assemblages during the re-creation of species-rich lowland hay meadows. Insect Conserv Divers 5:19-26. doi: 10.1111/j.1752-4598.2011.00132.x

Yamaura Y, Kawahara T, Lida S, Ozaki K (2008) Relative importance of the area and shape of patches to the diversity of multiple taxa. Conserv Biol 22:1513-1522. 
Table 1: Variables selected by the multiple regression program, stepAIC, for spider, carabid and plant $\alpha-$ diversity. $F$ and $P$ values are given only for the variables kept in the model by AIC. Direction corresponds to global trends of the best model fitting each variable to $\alpha$-diversity. Letters in bracket indicate best model type (l: log; c: cubic; L: linear; p: power; q: quadratic, ns: no significant).

\begin{tabular}{|c|c|c|c|c|c|c|c|c|c|c|}
\hline & & \multicolumn{3}{|c|}{ Spiders } & \multicolumn{3}{|c|}{ Carabids } & \multicolumn{3}{|c|}{ Plants } \\
\hline & & $F$ & $P$ & Direction & $F$ & $P$ & Direction & $F$ & $P$ & Direction \\
\hline \multirow[t]{9}{*}{ Local } & Mean vegetaion height & & & & & & & & & \\
\hline & Litter depth & & & & & & & & & \\
\hline & Mean temperature & 20.54 & $<0.001$ & $-(1)$ & & & & 8.36 & 0.005 & $\mathrm{~ns}$ \\
\hline & Precipitations & & & & 1.78 & 0.187 & & & & \\
\hline & Mean moisture index & 13.95 & $<0.001$ & $-(\mathrm{c})$ & 2.14 & 0.149 & & & & \\
\hline & $\begin{array}{l}\text { Mean continentality } \\
\text { index }\end{array}$ & 2.20 & 0.143 & & & & & 11.59 & $<0.001$ & $-(q)$ \\
\hline & Mean light index & & & & & & & 15.94 & $<0.001$ & $+(q)$ \\
\hline & Mean nutrient index & & & & & & & 43.66 & $<0.001$ & $-(\mathrm{q})$ \\
\hline & Flooding & 0.57 & 0.455 & & 1.48 & 0.229 & & 1.87 & 0.176 & \\
\hline \multirow[t]{6}{*}{ Landscape } & Grassland cover & 5.17 & 0.026 & $-(\mathrm{L})$ & 5.86 & 0.019 & $-(1)$ & & & \\
\hline & Urban cover & 10.54 & 0.002 & $+(\mathrm{L})$ & & & & & & \\
\hline & Water cover & & & & 2.36 & 0.129 & & 4.64 & 0.036 & $+(q)$ \\
\hline & Wood cover & 1.59 & 0.212 & & & & & & & \\
\hline & Lithography & 4.25 & $<0.001$ & & 2.43 & 0.036 & & 2.89 & 0.015 & \\
\hline & Area & & & & 0.65 & 0.424 & & & & \\
\hline \multirow[t]{5}{*}{ Connectivity } & Distance to the sea & & & & 4.37 & 0.041 & $\mathrm{~ns}$ & 5.25 & 0.026 & $\mathrm{~ns}$ \\
\hline & Distance to the river & 9.96 & 0.002 & $-(p)$ & 0.78 & 0.381 & & 3.86 & 0.054 & \\
\hline & Min distance to hedge & & & & & & & 0.05 & 0.822 & \\
\hline & $\begin{array}{l}\text { Beta index of } \\
\text { connectivity }\end{array}$ & 7.37 & 0.009 & $+(\mathrm{L})$ & 13.42 & $<0.001$ & $+(\mathrm{L})$ & 22.54 & $<0.001$ & $-(1)$ \\
\hline & $\begin{array}{l}\text { Index of } \\
\text { heterogeneity }\end{array}$ & & & & & & & 13.24 & $<0.001$ & ns \\
\hline
\end{tabular}


Table 2: Variables selected by the forward selection after canonical analysis of principal coordinates (CAP) on the $\beta$-diversity matrix for spiders, carabids, and plants. $F$ and $P$ values are given only for the variables kept in the model by AIC.

\begin{tabular}{|c|c|c|c|c|c|c|c|c|c|c|}
\hline & & \multicolumn{3}{|c|}{ Spiders } & \multicolumn{3}{|c|}{ Carabids } & \multicolumn{3}{|c|}{ Plants } \\
\hline & & $F$ & $P$ & Direction & $F$ & $P$ & Direction & $F$ & $P$ & Direction \\
\hline \multirow[t]{9}{*}{ Local } & $\begin{array}{l}\text { Mean vegetaion } \\
\text { height }\end{array}$ & & & & & & & & & \\
\hline & Litter depth & & & & & & & & & \\
\hline & Mean temperature & & & & 2.45 & 0.010 & + & & & \\
\hline & Precipitations & 2.56 & 0.010 & - & & & & 3.67 & 0.010 & - \\
\hline & Mean moisture index & 2.64 & 0.010 & - & & & & 4.21 & 0.010 & - \\
\hline & $\begin{array}{l}\text { Mean continentality } \\
\text { index }\end{array}$ & & & & & & & 3.35 & 0.010 & + \\
\hline & Mean light index & & & & & & & 4.21 & 0.010 & + \\
\hline & Mean nutrient index & & & & & & & 2.19 & 0.010 & - \\
\hline & Flooding & & & & 4.78 & 0.010 & - & 3.39 & 0.010 & - \\
\hline \multirow[t]{6}{*}{ Landscape } & Grassland cover & & & & & & & & & \\
\hline & Urban cover & 2.99 & 0.010 & + & & & & 1.83 & 0.030 & + \\
\hline & Water cover & & & & & & & & & \\
\hline & Wood cover & & & & & & & & & \\
\hline & bedrock type & 1.37 & 0.049 & & 1.73 & 0.010 & & 1.59 & 0.010 & \\
\hline & Area & & & & & & & & & \\
\hline \multirow[t]{6}{*}{ Connectivity } & Distance to the sea & & & & 2.21 & 0.060 & & 4.11 & 0.010 & + \\
\hline & Distance to the river & & & & 2.09 & 0.020 & - & 5.27 & 0.010 & - \\
\hline & Min distance to hedge & & & & & & & 4.44 & 0.010 & - \\
\hline & Bocage length & & & & & & & 2.79 & 0.020 & + \\
\hline & $\begin{array}{l}\text { Beta index of } \\
\text { connectivity }\end{array}$ & & & & & & & 2.09 & 0.030 & + \\
\hline & $\begin{array}{l}\text { Index of } \\
\text { heterogeneity }\end{array}$ & 2.43 & 0.010 & + & & & & 2.31 & 0.010 & + \\
\hline
\end{tabular}

